\title{
Roda de conversa virtual sobre questão socioambiental para a sensibilização dos
}

\author{
alunos \\ Virtual conversation wheel on socioenvironmental issues for student awarenes \\ Rueda de conversación virtual sobre assuntos socioambientales para la conciencia del estudiante
}

Recebido: 05/03/2021 | Revisado: 11/03/2021 | Aceito: 25/03/2021 | Publicado: 02/04/2021

Leilane Alves de Oliveira

ORCID: https://orcid.org/0000-0001-6002-5451 Universidade Federal de Mato Grosso, Brasil E-mail: Leilanyalves88@gmail.com

Carmen Wobeto

ORCID: https://orcid.org/0000-0002-8645-5203 Universidade Federal de Mato Grosso, Brasil E-mail: carmenwobeto2014@gmail.com

Patrícia Rosinke

ORCID: https://orcid.org/0000-0003-0433-7113 Universidade Federal de Mato Grosso, Brasil

E-mail: patirosinke@yahoo.com.br Julio Martinez Alves Oliveira

ORCID: https://orcid.org/0000-0002-3173-9444 Universidade Estadual Paulista, Brasil E-mail: juliooliveira1994@hotmail.com

\section{Resumo}

O elevado uso de agrotóxicos nas plantações agrícolas para combater pragas e insetos podem trazer muitos prejuízos à saúde das pessoas. Essas práticas são muito encontradas em lavouras da região norte de Mato Grosso. O objetivo deste estudo foi de utilizar as Tecnologias da informação e comunicação (TIC) para sensibilizar os alunos acerca do uso indiscriminado de agrotóxicos. Trata- se de um estudo qualitativo. O grupo participante da pesquisa foi composto por cinco alunos da escola estadual São Vicente de Paula no município de Sinop. Para levantamento de informações e constituição de dados, foi elaborado uma Roda de Conversa Virtual (RCV) como metodologia de ensino e aprendizagem e a análise dessas questões pode ser classificada como pesquisa qualitativa descritiva. Para o desenvolvimento da pesquisa, foi utilizado quatro momentos pedagógicos: pré questionário, roda de conversa virtual para a exposição de ideias, explanação do conteúdo feita pela professora, pós questionário. Os dados foram coletados pela professora por meio da aplicação de questionários e a RCV com aspectos de avaliação de conceitos e aspectos subjetivos. Sendo assim, a utilização da RCV é uma metodologia de ensino e aprendizagem que favorece a leitura de questões socioambientais, pois os alunos tiveram melhor argumentação sobre a temática, com conceitos mais fundamentado do que inicialmente com às questões relacionadas ao uso de agrotóxicos, ampliando os conhecimentos e a sensibilização dos alunos sobre as implicações do uso indiscriminadamente desses produtos na produção agrícola.

Palavras-chave: Roda de conversa; Leitura crítica; Questões socioambientais; Ensino.

\section{Abstract}

The high use of pesticides in agricultural plantations to combat pests and insects can cause many damage to people's health. These practices are widely found in crops in the northern region of Mato Grosso. The aim of this study was to use Information and Communication Technologies (ICT) to sensitize students about the indiscriminate use of pesticides. This is a qualitative study. The group participating in the research was composed of five students from the São Vicente de Paula state school in the municipality of Sinop. For gathering information and constituting data, a Virtual Conversation Wheel (RCV) was developed as a teaching and learning methodology and the analysis of these questions can be classified as qualitative descriptive research. For the development of the research, four pedagogical moments were used: pre-questionnaire, virtual conversation wheel for the exhibition of ideas, explanation of the content made by the teacher, post-questionnaire. The data were collected by the teacher through the application of questionnaires and the RCV with aspects of concept evaluation and subjective aspects. Therefore, the use of RCV is a teaching and learning methodology that favors the reading of socioenvironmental issues, as students had a better argument on the subject, with more grounded concepts than initially with questions related to the use of pesticides, expanding the students' knowledge and awareness of the implications of the indiscriminate use of these products in agricultural production.

Keywords: Conversation wheel; Critical reading; Socio-environmental issues; Teaching. 


\section{Resumen}

El alto uso de plaguicidas en las plantaciones agrícolas para combatir plagas e insectos puede causar muchos daños a la salud de las personas. Estas prácticas se encuentran ampliamente en los cultivos de la región norte de Mato Grosso. El objetivo de este estudio fue utilizar las Tecnologías de la Información y la Comunicación (TIC) para sensibilizar a los estudiantes sobre el uso indiscriminado de plaguicidas. Este es un estudio cualitativo. El grupo que participó en la investigación estuvo compuesto por cinco estudiantes de la escuela estatal São Vicente de Paula en el municipio de Sinop. Para la recolección de información y constitución de datos, se desarrolló una Rueda de Conversación Virtual (RCV) como metodología de enseñanza y aprendizaje y el análisis de estos temas se puede clasificar como investigación cualitativa descriptiva. Para el desarrollo de la investigación se utilizaron cuatro momentos pedagógicos: pre-cuestionario, rueda de conversación virtual para la exhibición de ideas, explicación del contenido realizada por el docente, post-cuestionario. Los datos fueron recolectados por el docente mediante la aplicación de cuestionarios y el RCV con aspectos de evaluación de conceptos y aspectos subjetivos. Así, el uso de RCV es una metodología de enseñanza y aprendizaje que favorece la lectura de temas socioambientales, ya que los estudiantes tuvieron una mejor argumentación sobre el tema, con conceptos más fundamentados que inicialmente con preguntas relacionadas con el uso de plaguicidas, ampliando el conocimiento de los estudiantes. y conciencia de las implicaciones del uso indiscriminado de estos productos en la producción agrícola.

Palabras clave: Rueda de conversación; Lectura crítica; Aspectos socioambientales; Ensenãnza.

\section{Introdução}

Os agrotóxicos são muito utilizados na agricultura e possuem a capacidade de lesionar ou matar determinados organismos vivos eliminando e controlando espécies indesejadas. O nome popular desse tipo de substância é mais conhecido como veneno, pois se trata de uma substância nociva (Beserra, 2017).

Na década de 1950 iniciou nos Estados Unidos a utilização em massa de agrotóxicos na agricultura por meio da Revolução Verde, com objetivo de aumentar a produtividade e modernizar a agricultura. No Brasil, esse movimento iniciou na década de 1960 e ganhou impulso na década de 1970 (Lopes; Albuquerque, 2018). A partir da Lei Federal nº 7.802, de 1989, foi adotado no Brasil o termo agrotóxico que traz o seguinte conceito em seu Artigo 2, Inciso I:

Os produtos e os agentes de processos físicos, químicos ou biológicos, destinados ao uso nos setores de produção, no armazenamento e beneficiamento de produtos agrícolas, nas pastagens, na proteção de florestas, nativas ou implantadas, e de outros ecossistemas e também de ambientes urbanos, hídricos e industriais, cuja finalidade seja alterar a composição da flora ou da fauna, a fim de preservá-las da ação danosa de seres vivos considerados nocivos (Lei Federal $n^{\circ} 7.802$, artigo 2, 1989).

O Estado de Mato Grosso tornou-se estratégico para a produção agropecuária capitalista mundial. Essa cadeia produtiva baseada na forma de produção de latifúndios monocultores, é dependente de milhões de litros de produtos químicos, e isso vem produzindo poluições ambientais, e prejuízos à saúde da população (Beserra, 2017).

Esse assunto está muito presente na região do médio-norte de Mato Grosso, que é contexto geográfico em que essa pesquisa foi desenvolvida, diante disso, considera-se relevante a discussão de questões socioambientais com os alunos para possibilitar o desenvolvimento de um olhar mais crítico da sua realidade.

Sendo assim, a utilização da Roda de Conversa (RC) é uma metodologia de ensino e aprendizagem que favorece a leitura de questões socioambientais, como às questões relacionadas ao uso de agrotóxicos. Devido ao momento atual em que estamos vivendo, a pandemia do covid-19 causada pelo vírus Sars-cov-2, as atividades foram desenvolvidas utilizando as tecnologias da informação e comunicação (TIC) para a realização da Roda de Conversa Virtual (RCV).

O trabalho foi desenvolvido tendo como norteadora a seguinte questão: A Roda de Conversa Virtual é uma metodologia de ensino que pode possibilitar uma leitura mais crítica da realidade relacionado ao uso de agrotóxicos?

Diante desse questionamento, estabeleceu-se como objetivos específicos: a) Conhecer as percepções prévias dos alunos sobre o uso de agrotóxicos; b) sensibilizar os alunos sobre as implicações do uso indiscriminadamente de agrotóxicos na produção agrícola; c) avaliar se as atividades pedagógicas contribuíram para sensibilização dos alunos sobre questão socioambiental. 


\section{Questão Socioambiental: a utilização de agrotóxicos no norte de Mato Grosso}

Há importantes críticas à condução de um processo de ensino e educação que se preocupa em apenas transmitir conhecimentos aos alunos (Aranha, 2006). Nesse tipo de educação, denominada de educação bancária, o educador conduz os educandos à memorização dos conteúdos. Ao contrário dessa educação, temos a educação problematizadora que rompe com os esquemas verticais da educação bancária, comprometida com a libertação (Freire, 2005).

De acordo com Santos (2007), essa abordagem na perspectiva de Paulo Freire que visa à educação problematizadora, busca o desenvolvimento de valores e atitudes aliados à capacidade de tomada de decisões. Na educação problematizadora, as questões sociais apresentadas no ensino de ciências possibilitam trabalhar aspectos políticos, ideológicos, culturais e éticos da ciência contemporânea.

De acordo com Pérez (2012) o ensino de Ciências com ênfase CTSA tem por objetivo a emancipação dos alunos fazendo com que eles problematizem a Ciências e participem (Pérez, 2012). No enfoque CTSA, destaca-se a escolha de temas que estão relacionados a discussões que se desenvolve na sociedade atual, controvérsias ou temas diretamente relacionados aos conhecimentos científicos e/ou tecnológico com grande impacto na sociedade. Essas discussões podem favorecer o ensino em busca da cidadania.

A Base Nacional Comum Curricular (BNCC) (Brasil, 2017) é um documento de caráter normativo que se refere às aprendizagens essenciais que os alunos devem desenvolver durante sua trajetória na escola. Este documento está orientado pelos princípios éticos, políticos e estratégicos visando à formação humana para a construção de uma sociedade justa, democrática e inclusiva. Em se tratando da BNCC, considerou-se as seguintes competências e habilidades:

COMPETÊNCIA ESPECÍFICA 1. Analisar fenômenos naturais e processos tecnológicos, com base nas interações e relações entre matéria e energia, para propor ações individuais e coletivas que aperfeiçoem processos produtivos, minimizem impactos socioambientais e melhorem as condições de vida em âmbito local, regional e global. (EM13CNT104) Avaliar os benefícios e os riscos à saúde e ao ambiente, considerando a composição, a toxicidade e a reatividade de diferentes materiais e produtos, como também o nível de exposição a eles, posicionando-se criticamente e propondo soluções individuais e/ou coletivas para seus usos e descartes responsáveis (BNCC, 2017, p. 357)

Diante desse contexto, surge o tema que é muito discutido em nossa sociedade, o uso de agrotóxicos, que está muito presente na região do médio-norte de Mato Grosso. A partir do ano de 2008, o Brasil se tornou o maior consumidor de agrotóxicos, o uso desses produtos de forma exagerada acarreta muitos problemas, afetando o meio ambiente e a saúde das pessoas, principalmente dos agricultores, a fauna, a flora, entre outros (Viero et al., 2016).

De acordo com dados da Associação Brasileira da Indústria Química (Abiquim), que nos períodos de 2007 e 2013, o Estado de Mato Grosso estava em primeiro lugar entre os estados que mais consumiram agrotóxicos, com aproximadamente 207 milhões de litros em suas plantações. Os estudos mostram cada vez mais os impactos negativos à saúde em relação ao uso indiscriminado desses produtos (Silva et al., 2019).

\section{Roda de Conversa Virtual e leitura crítica da realidade}

O ano de 2020 está sendo marcado pela pandemia da Covid-19. Sendo assim, foi preciso desenvolver as atividades pedagógicas priorizando a saúde de todos. Diante desse contexto, a utilização das Tecnologias da Informação e Comunicação (TIC), nos coloca numa situação menos desfavorável.

As TIC se tornaram mais sofisticadas podendo ser utilizadas por meio de vários recursos tecnológicos como: áudios, vídeos, satélites, computadores, celulares, Internet e suas inúmeras possibilidades (Modrow; Silva, 2013). O uso da TIC pode 
ser utilizado pelos profissionais da educação, sendo ferramentas facilitadoras do ensino, contudo a mediação do professor é indispensável.

A RCV é uma metodologia de ensino e aprendizagem para abordar assuntos sobre o uso de agrotóxicos favorecendo a aprendizagem de conhecimentos e leitura crítica, dessa forma, acredita-se que o trabalho apresenta relevância e importância científica e social. A RCV é um espaço de diálogo para troca de saberes. O autor Paulo Freire (2014) relata que:

O diálogo se impõe no caminho pelo qual os homens ganham significação enquanto homens. Por isto, o diálogo é exigência existencial. E, se ele é o encontro em que se solidarizam o refletir e o agir de seus sujeitos endereçados ao mundo a ser transformado e humanizado, não pode reduzir-se a um ato de depositar ideias de um sujeito no outro, nem tampouco tornar-se simples troca de ideias a serem consumidas pelos permutantes. Não é também discussão guerreira, polêmica, entre sujeitos que não aspiram a comprometer-se com a pronúncia do mundo, nem a buscar a verdade, mas a impor a sua (Paulo Freire, p.19, 2014).

\section{Metodologia}

Trata-se de um estudo qualitativo. Nesse tipo de pesquisa pretende-se utilizar as informações e a reflexão sobre os dados para intervir no processo de ensino e aprendizagem de ciências de forma a contribuir com uma formação mais condizente com as propostas atuais da educação escolar (Chizzotti, 2005). Nos métodos quantitativos, faz-se a coleta de dados quantitativos ou numéricos por meio do uso de medições de grandezas e obtém-se por meio da metrologia, números com suas respectivas unidades (Pereira et al., 2018).

O grupo participante da pesquisa foi composto por cinco alunos da escola estadual São Vicente de Paula no município de Sinop. Para levantamento de informações e constituição de dados, foi elaborado uma Roda de Conversa Virtual como metodologia de ensino e aprendizagem.

Os alunos da rede estadual de ensino estão sem aulas presenciais devido à pandemia do covid-19. Sendo assim, foi realizado um projeto intitulado "A experimentação e a ludicidade no ensino de Ciências: o olhar do professor" desenvolvido na disciplina de Ensino de Química do mestrado do Programa de Pós Graduação de Ensino de Ciências da Natureza e Matemática da UFMT que teve aprovação do comitê de Ética em Pesquisa (CEP). O desenvolvimento do estudo seguiu as diretrizes e normas para a pesquisa envolvendo seres humanos por meio do CEP (UFMT). Número: 4.145.162 CAAE 31576320.9 .0000 .8097$.

Para a realização das atividades, foi feito o convite para 10 alunos e somente 5 alunos aceitaram participar dos momentos pedagógicos. Os encontros pedagógicos foram realizados pelo jitsi meet, com a participação de 5 alunos do ensino médio. O primeiro momento pedagógico foi realizado no dia 14/07/2020 e durou 50 minutos. Primeiramente, os alunos responderam ao questionário prévio e em seguida iniciamos a Roda de Conversa Virtual, por meio de questionamentos sobre o uso de agrotóxicos e seus impactos no meio ambiente e na saúde humana, com o objetivo de conhecer as percepções prévias dos alunos sobre o uso de agrotóxicos.

Após a RCV a professora apresentou sobre conceito científico de agrotóxicos, breve histórico sobre os agrotóxicos, fórmulas químicas de alguns agrotóxicos.

O segundo momento pedagógico foi realizado no dia 15/07/2020, com duração de aproximadamente 40 minutos, com a aula abordando fórmulas químicas de alguns agrotóxicos, impactos do agrotóxico no meio ambiente e na saúde, horta, alimentos orgânicos.

No terceiro momento pedagógico, os alunos receberam dois vídeos pelo whatsapp para assistir e trazer discussões para o quarto momento pedagógico. Os vídeos referiam-se sobre o conceito de agrotóxicos e seus impactos no ambiente e na saúde. O objetivo do segundo e terceiro momento pedagógico foi sensibilizar os alunos sobre as implicações do uso indiscriminadamente de agrotóxicos na produção agrícola 
O último momento pedagógico foi realizado no dia 16/07/2020, com duração de 30 minutos. Neste momento, foi realizado a RCV com os mesmos questionamentos feitos na primeira RCV, com o objetivo de avaliar se as atividades pedagógicas contribuíram para sensibilização dos alunos sobre esta questão socioambiental.

\section{Resultados e Discussões}

Para manter o anonimato dos alunos participantes da pesquisa os mesmos foram identificados como A, B, C, D, E. As ações dessa pesquisa foram desenvolvidas por meio de TIC, no qual na RCV trataram-se de assuntos relacionados ao uso de agrotóxicos. Os momentos pedagógicos com os alunos foram planejados para atender aos objetivos propostos, com duração de 3 horas. Dessa forma, estruturou-se 4 momentos com os alunos: pré questionário, roda de conversa virtual para a exposição de ideias, explanação do conteúdo feita pela professora, pós questionário. Essa estruturação está organizada no Quadro 1.

Quadro 1. Momentos pedagógicos da pesquisa.

\begin{tabular}{|c|c|}
\hline MOMENTOS DA PESQUISA & ATIVIDADES PEDAGÓGICAS \\
\hline Questionário antes da atividade pedagógica & $\begin{array}{l}\text { 1. Onde você observa a Ciência na sua vida? Cite exemplos e explique. } \\
\text { 2.Na sua opinião, a Escola ajuda a compreender a vida e a Ciência. } \\
\text { 3.Os estudos na Escola mudaram a sua forma de ver o mundo a sua } \\
\text { volta. Exemplifique. } \\
\text { 4.Nas aulas de Ciências você realizou atividades experimentais? } \\
\text { Quais? }\end{array}$ \\
\hline $\begin{array}{l}\text { Roda de Conversa Virtual - exposição das } \\
\text { ideias e conhecimentos prévios dos alunos. }\end{array}$ & $\begin{array}{l}\text { 1.Você sabe o que é agrotóxico? } \\
\text { 2.Cite o nome de agrotóxicos que você conhece? } \\
\text { 3.Quais os efeitos dos agrotóxicos na saúde? } \\
\text { 4.Quais os impactos dos agrotóxicos no meio ambiente? }\end{array}$ \\
\hline Explanação do conteúdo & $\begin{array}{l}\text { - Conceito de agrotóxicos; } \\
\text { - Breve Histórico sobre os agrotóxicos; } \\
\text { - Fórmulas químicas de alguns agrotóxicos; } \\
\text { - Impactos do agrotóxico no meio ambiente; } \\
\text { - Impactos dos agrotóxicos na saúde. }\end{array}$ \\
\hline Apresentação de vídeos & $\begin{array}{l}\text { Link do vídeo 1: } \\
\text { https://www.youtube.com/watch?v=46Hpo } 8 n \_f A 4 \& t=22 \text { s } \\
\text { Link do Vídeo2: } \\
\text { https://www.youtube.com/watch?v=B_V4VEYgq04 }\end{array}$ \\
\hline $\begin{array}{l}\text { Roda de Conversa Virtual - discussão para } \\
\text { avaliar os conhecimentos adquiridos com a } \\
\text { aula. }\end{array}$ & $\begin{array}{l}1 \text { Você sabe o que é agrotóxico? } \\
2 \text { Cite o nome de agrotóxicos que você conhece? } \\
3 \text { Quais os efeitos dos agrotóxicos na saúde? } \\
4 \text { Quais os impactos dos agrotóxicos no meio ambiente? }\end{array}$ \\
\hline Questionário após a atividade pedagógica & $\begin{array}{l}\text { 1.Responda sobre a atividade realizada na sala de aula: } \\
\text { 2.Qual foi o assunto? } \\
\text { 3.O que você ou seu grupo fez? } \\
\text { 4.O que você aprendeu? } \\
\text { 5.Estas atividades que você realizou contribuíram para mudar sua } \\
\text { opinião ou forma de compreender as coisas a sua volta? Explique. }\end{array}$ \\
\hline
\end{tabular}

Fonte: Autoras. 
O Quadro 1 apresentou os quatro momentos pedagógicos desenvolvidos na RCV. A metodologia foi desenvolvida com ênfase na questão norteadora, os agrotóxicos, sendo classificada como pesquisa qualitativa descritiva. Os dados foram coletados pela professora por meio da aplicação de questionários e pelas gravações das RCV, com aspectos de avaliação subjetiva dos conceitos, para avaliar a sensibilização dos educandos para questões socioambiental. Para registros da pesquisa, foi utilizado equipamentos de áudio e vídeo. As falas consideradas mais relevantes foram organizadas e citadas no trabalho exatamente como explanadas pelo participante da pesquisa.

Sendo assim, os questionários são ferramentas de grande abrangência para a pesquisa, pois apresentam uma resposta rápida, abrangendo um maior número de dados analisáveis e garante o anonimato dos participantes, contudo, tem pontos negativos, como por exemplo: as descrições podem ser superficiais e o dado coletado é descrito ao invés de ser explicado (Moreira; Caleffe, 2008).

No primeiro momento pedagógico os alunos ficaram um pouco tímidos, mas depois foram discutindo e expondo seus conhecimentos e opiniões em relação ao tema. Neste momento podemos observar que os alunos expuseram os pontos positivos da ciência e nenhum deles mencionou os aspectos negativos que a ciência pode trazer para a sociedade. Podemos perceber que eles possuem um olhar da ciência como algo que é somente benéfico para as pessoas. O quadro 2 apresenta as perguntas e as repostas de alguns alunos.

Quadro 2. Questionário aplicado antes da atividade pedagógica.

\begin{tabular}{|c|c|}
\hline Perguntas & Respostas de alguns alunos \\
\hline $\begin{array}{l}\text { 1. Onde você observa a Ciência na sua vida? Cite } \\
\text { exemplos e explique. }\end{array}$ & $\begin{array}{l}\text { Aluno D: eu observo na composição no refri, suco de } \\
\text { pacotinho e também nos venenos. } \\
\text { Aluno C: em quase tudo, como por exemplo, os } \\
\text { remédios, os produtos de higiene pessoal, produtos } \\
\text { de limpeza e etc. Por que feitos em laboratório com } \\
\text { química. } \\
\text { Aluno A: na hora de cozinhar porque é aonde } \\
\text { misturamos vários ingredientes. } \\
\text { Aluno E: sim, o gelo que coloca no teres do liquido } \\
\text { passa para o sólido. }\end{array}$ \\
\hline $\begin{array}{l}\text { 2.Na sua opinião a Escola ajuda a compreender a } \\
\text { vida e a Ciência. }\end{array}$ & $\begin{array}{l}\text { Aluno D: sim. } \\
\text { Aluno } C: \text { talvez. }\end{array}$ \\
\hline $\begin{array}{l}\text { 3.Os estudos na Escola mudaram a sua forma de ver } \\
\text { o mundo a sua volta. Exemplifique. }\end{array}$ & $\begin{array}{l}\text { Aluno D: sim, percebemos que cada coisa tem sua } \\
\text { composição. } \\
\text { Aluno C: sim, como observar que a ciência está no } \\
\text { nosso dia a dia. } \\
\text { Aluno A: sim, porque lá tem coisas que são apenas } \\
\text { matérias e que acaba sendo exemplo de vida. }\end{array}$ \\
\hline $\begin{array}{l}\text { 4.Nas aulas de Ciências você realizou atividades } \\
\text { experimentais? Quais? }\end{array}$ & Aluno D:sim, só não lembro o nome da experiência. \\
\hline
\end{tabular}

Fonte: Autoras. 
O Quadro 2 apresentou a aplicação do questionário antes da atividade pedagógica. Na RCV os alunos dialogaram sobre os conceitos de agrotóxicos e seus impactos na saúde e meio ambiente, porém basearam-se no senso comum e não souberam argumentar de forma científica. Como dito anteriormente, podemos perceber que os alunos não mencionaram o lado negativa da ciência para as pessoas. No Quadro 3 está organizado o desenvolvimento da RCV entre o professor e os alunos.

Quadro 3. Roda de Conversa Virtual desenvolvida antes da exposição da aula.

\begin{tabular}{|l|l|}
\hline Perguntas RCV & Respostas de alguns alunos na RCV \\
\hline 1-Você sabe o que é agrotóxico? & $\begin{array}{l}\text { Aluno A: É aquele para matar inseto. } \\
\text { Aluno D: Veneno. }\end{array}$ \\
\hline 2-Cite o nome de agrotóxicos que você conhece. & Todos falaram que não sabia. \\
\hline 3--Quais os efeitos dos agrotóxicos na saúde? & $\begin{array}{l}\text { Aluno D: Como ele é veneno, se você consumir, pode } \\
\text { matar, então eles usam em plantações e da plantação } \\
\text { vai para a fábrica para tirar o agrotóxico da comida. }\end{array}$ \\
\hline $\begin{array}{l}\text { 4-Quais os impactos dos agrotóxicos na saúde e meio } \\
\text { ambiente? }\end{array}$ & $\begin{array}{l}\text { Aluno D: Agrotóxico que é ruim pode matar insetos e } \\
\text { outros que pode danificar solo. }\end{array}$ \\
\hline
\end{tabular}

Fonte: Autoras.

No Quadro 3, foi percebido, pelas falas dos alunos, que o uso de agrotóxico é prejudicial somente para insetos e o solo. No Quadro 4 está organizado o momento pedagógico da RCV após a explanação do conteúdo feito pelo professor.

Quadro 4. Roda de Conversa Virtual após a explanação do conteúdo.

\begin{tabular}{|l|l|}
\hline Perguntas RCV & Respostas dos alunos na RCV \\
\hline 1-Você sabe o que é agrotóxico? & $\begin{array}{l}\text { Aluno A: Produtos químicos usados nas plantações e } \\
\text { lavouras para combater pragas e doenças. }\end{array}$ \\
\hline 2-Cite o nome de agrotóxicos que você conhece. & $\begin{array}{l}\text { Aluno D: Inseticidas, herbicidas. } \\
\text { Aluno A: Fumigantes. }\end{array}$ \\
\hline 3--Quais os efeitos dos agrotóxicos na saúde? & $\begin{array}{l}\text { Aluno D: causa intoxicação alimentar, câncer e } \\
\text { problemas na formação do feto. }\end{array}$ \\
\hline $\begin{array}{l}\text { 4-Quais os impactos dos agrotóxicos na saúde e meio } \\
\text { ambiente? }\end{array}$ & Aluno A: contaminação da água e solo. \\
\hline
\end{tabular}

Fonte: Autoras.

No Quadro 4 podemos perceber que houve um avanço em relação ao tema agrotóxico, pois os alunos ampliaram sua visão sobre a ciência e mencionaram os efeitos negativos do uso indiscriminado de agrotóxicos. O Quadro 5 apresenta questionário aplicado aos alunos após as atividades pedagógicas. 
Quadro 5. Questionário aplicado após as atividades pedagógicas

\begin{tabular}{|l|l|}
\hline Questionário antes da atividade pedagógica & Respostas de alguns alunos \\
\hline 1.Qual foi o assunto? & $\begin{array}{l}\text { Aluno C: Uso de agrotóxicos. } \\
\text { Aluno D: Agrotóxicos. } \\
\text { Aluno A: Agrotóxicos e seus impactos na nossa vida } \\
\text { como no meio ambiente. }\end{array}$ \\
\hline 2.O que você ou seu grupo fez? & $\begin{array}{l}\text { Aluno C: assistimos vídeos e dialogamos sobre o } \\
\text { assunto. } \\
\text { Aluno D: estudamos sobre o assunto e debatemos e } \\
\text { vimos vídeo do assunto. } \\
\text { Aluna A: Debatemos o assunto e realizamos algumas } \\
\text { atividades. }\end{array}$ \\
\hline $\begin{array}{l}\text { 3.O que você aprendeu? } \\
\text { Aluno C: que os agrotóxicos são prejudiciais a saúde } \\
\text { do ser humano, dos animais, das plantas. } \\
\text { Aluno A: aprendi o conceito de agrotóxicos e seus } \\
\text { benefícios e malefícios. }\end{array}$ \\
\hline $\begin{array}{l}\text { Aluno C: Sim, até então, não sabia porque os } \\
\text { para você mudar sua opinião ou forma de } \\
\text { compreender as coisas a sua volta? Explique. }\end{array}$ \\
$\begin{array}{l}\text { agrotóxicos foram criados, e não sabia que era para } \\
\text { aumentar a produçáo, agora sei quantos problemas } \\
\text { ele pode causar. } \\
\text { Aluno D:sim porquê as vezes compramos frutas } \\
\text { legumes etc.... pelo mais bonito mais nem sempre o } \\
\text { mais bonito é melhor. } \\
\text { Aluno A: Sim, porque eu não tinha conhecimento } \\
\text { sobre os danos que causa á nossa saúde. }\end{array}$ \\
\hline
\end{tabular}

Fonte: Autoras.

Nos dois últimos momentos pedagógicos, os alunos citaram os prejuízos que podem ser causados ao meio ambiente e também para a saúde das pessoas. Além disso, expressaram com suas falas o conhecimento científico e não argumentaram apenas baseado no senso comum.

Após a explanação dos conteúdos relacionados a história, conceitos de agrotóxicos e impactos na saúde e meio ambiente, percebeu-se que os alunos ampliaram seus conhecimentos sobre o uso indiscriminado de agrotóxicos e passaram a desenvolver um olhar mais crítico da sua realidade. Sendo assim, a RCV contribuiu em uma melhor argumentação sobre a temática, pois os alunos utilizaram conceitos científicos para explicar sobre o uso indiscriminado de agrotóxicos e relataram os pontos negativos desses produtos no ambiente e na saúde das pessoas.

A autora Nunes (2019) relata que a RC é uma metodologia importante para ser utilizada, pois melhora na argumentação sobre o tema. Neste sentido, os alunos saberão argumentar de forma científica sobre a temática agrotóxicos, com uma leitura mais fundamentada, considerando não apenas aspectos relacionados à sua vivência. 


\section{Conclusão}

Na região do Norte de Mato Grosso há elevado uso de agrotóxicos nas plantações agrícola para combater pragas e insetos, podendo trazer muitos prejuízos à saúde das pessoas e ao meio ambiente. Devido a isso, nesta pesquisa procurou-se sensibilizar os alunos por meio da RCV e explanação de conteúdos científicos, realizados em quatro momentos pedagógicos.

Neste trabalho, pode-se concluir que a utilização da RCV é uma metodologia de ensino e aprendizagem que favorece a leitura de questões socioambientais, como às questões relacionadas ao uso de agrotóxicos, pois observamos que houve ampliação dos conhecimentos e sensibilização dos alunos sobre as implicações do uso indiscriminadamente de agrotóxicos na produção agrícola. Embora o estudo apresente limitações, ele traz à tona dados importantes para discussão do tema. Novas pesquisas podem ser realizadas por meio de aplicação de questionários e inquéritos.

\section{Agradecimentos}

Agradeço aos professores pela atenção e paciência e aos alunos pela participação voluntária na pesquisa.

\section{Referências}

Aranha, L. A. (2006). Filosofia da Educação. (3a ed.), Moderna.

Associação Brasileira da Indústria Química (ABIQUIM). O desempenho da indústria química brasileira. https://abiquim.org.br/industriaQuimica. Acessado no dia 07/08/2020.

Beserra, L. (2017). Agrotóxicos, vulnerabilidades socioambientais e saúde: uma avaliação participativa em municípios da bacia do rio Juruena, Mato Grosso. 2017. 140f. Dissertação (Mestrado em Saúde Coletiva). Programa de Pós-Graduação em Saúde Coletiva, do Instituto de Saúde Coletiva da Universidade Federal de Mato Grosso Cuiabá.

BrasiL. Congresso Nacional. Lei $\mathrm{n}^{\circ}$ 7.802, de 11 de julho de 1989. Dispõe sobre a pesquisa, a experimentação, a produção, a embalagem e rotulagem, o transporte, o armazenamento, a comercialização, a propaganda comercial, a utilização, a importação, a exportação, o destino final dos resíduos e embalagens, o registro, a classificação, o controle, a inspeção e a fiscalização de agrotóxicos, seus componentes e afins, e dá outras providências. Diário Oficial da União.

Brasil. (2019). Ministério da educação. Temas contemporâneos transversais na BNCC: contexto histórico e pressupostos pedagógicos .

CFMV, Conselho federal de medicina veterinária. Saúde Única. http://portal.cfmv.gov.br/pagina/index/id/162/secao/8 .

Chizzotti, A. (2005). Pesquisa em ciências humanas e sociais. (7a ed.), Cortez.

Freire, P. (2005). Pedagogia do Oprimido. (44a ed.), Editora Paz e Terra.

Freire, P. (2014). Pedagogia do oprimido. (56a ed.), Paz e Terra.

Lopes, C. V. A. Albuquerque, G. S. (2018). Agrotóxicos e seus impactos na saúde humana e ambiental: uma revisão sistemática. Saúde de debate. 42(117), 518-534.

Modrow, E. S., \& Silva, M. B. (2013). Os desafios da escola pública paranaense na perspectiva do professor PDE. Versão On-line ISBN 978-85-8015-076-6 Cadernos PDE.

Moreira, H., \& Caleffe, L. G. (2008). Metodologia da pesquisa para o professor pesquisador. (2a ed.), Lamparina.

Nunes, J. V. (2019). Roda de conversa e a leitura de uma questão socioambiental na formação docente. 55p. Trabalho de Conclusão de Curso (Monografia apresentada como requisito para conclusão do curso Licenciatura em ciências naturais e matemática habilitação em química) Universidade Federal de Mato Grosso, Sinop.

Perez, L. F. M. (2012). Ensino de ciências com enfoque ciência, tecnologia, sociedade e ambiente (CTSA)a partir de questões sociocientíficas (QSC). São Paulo: Editora UNESP. p. 55- 61.

Pereira, A. S., Shitsuka D. M., Parreira F. J., \& Shitsuka R. (2018). Metodologia da pesquisa científica. UFSM. https://repositorio.ufsm.br/bitstream/handle/1/15824/Lic_Computacao_Metodologia-Pesquisa-Cientifica.pdf?sequence=1 .

Santos, W. L. P. (2007). Contextualização no ensino de ciências por meio de temas CTS em uma perspectiva crítica. Ciência \& Ensino.

Silva, D. O. S., Ferreira, M. J. M. F., Silva, S. A., Santos, M. A., Santos, H. D. H., \& Silva, A. M. C. (2013). Exposição aos agrotóxicos e intoxicações agudas em região de intensa produção agrícola em Mato Grosso. Epidemiol. Serv. Saude, Brasília, 28(3):e2018456, 2019.

Viero, C. M. C. S., Vazz, M. R. C., Costa, V. Z., \& Beck, C. L. C. (2016). Sociedade de risco: o uso dos agrotóxicos e implicações na saúde do trabalhador rural. Escola Anna Nery 20(1). 